Article

\title{
Effects of Marine Oils, Digested with Human Fluids, on Cellular Viability and Stress Protein Expression in Human Intestinal Caco-2 Cells
}

\author{
Cecilia Tullberg ${ }^{1, *}$ (D), Gerd Vegarud ${ }^{2}$, Ingrid Undeland ${ }^{1}$ (D) and Nathalie Scheers ${ }^{1, *}$ \\ 1 Division of Food and Nutrition Science, Department of Biology and Biological Engineering, Chalmers \\ University of Technology, Kemigården 4, 41296 Gothenburg, Sweden; undeland@chalmers.se \\ 2 Division of Food Proteins, Structure and Biological Function, Department of Chemistry, Biotechnology and \\ Food Science, Norwegian University of Life Sciences, Chr. M. Falsens vei 1, 1432 Ås, Norway; \\ gerd.vegarud@nmbu.no \\ * Correspondences: cecilia.tullberg@chalmers.se (C.T.); nathalie.scheers@chalmers.se (N.S.); \\ Tel.: +46-31-772-38-16 (C.T.); +46-31-772-38-21 (N.S.)
}

Received: 31 August 2017; Accepted: 1 November 2017; Published: 4 November 2017

\begin{abstract}
In vitro digestion of marine oils has been reported to promote lipid oxidation, including the formation of reactive aldehydes (e.g., malondialdehyde (MDA) and 4-hydroxy-2-hexenal (HHE)). We aimed to investigate if human in vitro digestion of supplemental levels of oils from algae, cod liver, and krill, in addition to pure MDA and HHE, affect intestinal Caco-2 cell survival and oxidative stress. Cell viability was not significantly affected by the digests of marine oils or by pure MDA and HHE $(0-90 \mu \mathrm{M})$. Cellular levels of HSP-70, a chaperone involved in the prevention of stress-induced protein unfolding was significantly decreased $(14 \%, 28 \%$, and $14 \%$ of control for algae, cod and krill oil, respectively; $p \leq 0.05$ ). The oxidoreductase thioredoxin-1 (Trx-1) involved in reducing oxidative stress was also lower after incubation with the digested oils $(26 \%, 53 \%$, and $22 \%$ of control for algae, cod, and krill oil, respectively; $p \leq 0.001$ ). The aldehydes MDA and HHE did not affect HSP-70 or Trx-1 at low levels (8.3 and $1.4 \mu \mathrm{M}$, respectively), whilst a mixture of MDA and HHE lowered Trx-1 at high levels $(45 \mu \mathrm{M})$, indicating less exposure to oxidative stress. We conclude that human digests of the investigated marine oils and their content of MDA and HHE did not cause a stress response in human intestinal Caco-2 cells.
\end{abstract}

Keywords: Caco-2; human digests; lipid oxidation; marine oil; HHE; MDA; Trx-1; HSP-70

\section{Introduction}

Intake of marine omega-3 fatty acids, i.e., the long-chain n-3 polyunsaturated fatty acids (LC n-3 PUFA) eicosapentaenoic acid (EPA), and docosahexaenoic acid (DHA), has been associated with beneficial health effects related to e.g., cardiovascular diseases [1,2]. Intake of marine oils high in EPA and DHA as dietary supplements, rather than ingesting them as a part of a complex seafood diet, has raised concerns regarding the stability of the pure oils, i.e., oils being separated from their native matrix. Marine oils are highly susceptible to peroxidation during storage and processing, and there are also indications of that the oils oxidize during gastrointestinal (GI) digestion [3-5], which is supported by several review [4,5], in vitro [3,6-9], and animal studies [10] of simulated GI digestion of marine oils.

Malondialdehyde (MDA) is one of the most well-known lipid oxidation products that is formed from PUFA. MDA is often used as a biomarker for lipid oxidation [11-14]. MDA has been attributed possible genotoxic features due to its ability to crosslink proteins and DNA, and it has also been associated with the development of cardiovascular disease, as reviewed by Del Rio et al. [15], and Uchida [16]. $\alpha, \beta$-unsaturated aldehydes are thought to be more toxic than MDA, and are 
more reactive toward nucleophiles due to the hydroxyl-group, which is positioned close to the double bond [13,17]. One such aldehyde is 4-hydroxy-2-hexenal (HHE), which is derived from $n$-3 PUFAs [18,19], and is hence an important endpoint in the investigation of oxidative stability of marine oils.

Fish oil has been associated with anti-inflammatory properties, such as the down-regulation of inflammatory cytokines (e.g., TNF- $\alpha$, IL-6), the increase of cellular membrane content of EPA and DHA, and the decrease of cellular membrane content of arachidonic acid (AA), all in healthy humans [20]. Also, EPA and DHA supplementation has led to decreased T-cell reactivity in cell and animal studies [20]. In murine models, high fat LC $n$-3 PUFA diets have been observed to decrease the levels of inflammation markers in plasma (IL-6 and MCP-1) [21] and in the spleen (NF-KB) [22], the same markers that increased in the study where mice were fed with an oxidized diet [10]. In another murine study, in which the mice were fed an oxidized LC n-3 PUFA diet, inflammatory markers such as NF- $\kappa B$ and glutathione peroxidase increased [10]. In addition, it was observed that HHE given orally to the mice was associated with an inflammatory response, as well as the formation of HHE-adducts. HHE in plasma increased significantly in mice given the oxidized LC $n-3$ PUFA diet [10]. In the search for sustainable LC n-3 PUFA rich substitutes to the traditional cod liver oil and fish oil [23,24], krill and microalgae oil (in this article referred to as algae oil) are two plausible candidates. Krill oil contains more EPA when compared to algae oil, while algae produce its own DHA, and therefore the oil is richer in this fatty acid (FA) [25]. They are both high in naturally occurring antioxidants, e.g., astaxanthin in krill oil [25,26], and phenolic compounds, flavonoids, sterols, and $\beta$-carotene in algae oil [27]. A specific feature of krill oil is that most of the LC n-3 PUFA are bound in phospholipids. In microalgae, fish muscle, and liver, the LC n-3 PUFA are incorporated in triacylglycerols (TG).

In this study, we investigated the effects of in vitro digests of three marine oils (cod liver oil, krill oil, and algae oil) generated with human digestive fluids on a cultured human intestinal epithelium (Caco-2 cell line). We measured the content of the secondary oxidation products MDA and HHE in the digests, and exposed the epithelium to pure MDA and HHE at these levels and above. We also measured the aldehyde levels in the basal medium. In addition, we examined stress-related protein levels in the Caco-2 cells with proteome profiler arrays to evaluate if the cells were exposed to stress during the various treatments.

\section{Materials and Methods}

\subsection{Materials}

The pre-cursor for MDA standard 1,1,3,3-tetraethoxypropane (TEP), 2,4-dinitrophenylhydrazine (DNPH), and reagents used for cell experiments were all purchased from Sigma-Aldrich (Schnelldorf, Germany). 4-hydroxy-2-hexenal (HHE), 4-hydroxy-2-nonenal (HNE), and 4-oxy-2-nonenal (ONE) standards were supplied from Cayman Chemicals (Ann Arbor, MI, USA). Media and supplements that were needed for cell culture maintenance were purchased from PAA (Pasching, Austria), and disposables in polystyrene used for cell cultivation and maintenance were bought from Corning (San Francisco, MA, USA). The human cell stress array kit was purchased from Bio-techne (Abingdon, UK).

\subsection{Collection of Human Digestive Fluids}

Saliva was collected from seven healthy fasting volunteers at Chalmers University of Technology (Gothenburg, Sweden) in November 2015. Saliva was collected in the morning by sterile straw pipets (Kemikalia; Skurup, Sweden) and volunteers were shown pictures of fish dishes to stimulate spontaneous drooling during collection. Saliva was pooled to eliminate individual effects, centrifuged, and stored at $-80^{\circ} \mathrm{C}$.

Human gastric juice (HGJ) and human duodenal juice (HDJ) were aspirated from six healthy volunteers at Lovisenberg Diakonale Hospital (Oslo, Norway), as described by Ulleberg et al. [28], 
and Holm et al. [29]. The volunteers were semi-fasting using a stimulatory solution and aspiration was done using gastroscopy and a triple lumen tube (Maxter Catheters, Marseille, France), aspiration details are further described by Ulleberg et al. [28]. Aspirates were pooled, enzyme activities, and $\mathrm{pH}$ of the human GI fluids were recorded according to Minekus et al. [30], and the HGJ and HDJ were stored separately at $-80^{\circ} \mathrm{C}$. All of the participants in the study were volunteers with informed consent, and the study was performed according to the Declaration of Helsinki. Ethical approval was received from the Norwegian Regional Ethics Committee (project no. 2012/2230, Biobank no. 2012/2210).

The human digestive fluids were characterized according to Minekus et al. [30], and enzymatic activities were measured in connection to the in vitro digestions. The pepsin activity of HGJ was $1200 \mathrm{U} / \mathrm{mL}$, the gastric lipase activity in the HGJ was $16 \mathrm{U} / \mathrm{mL}$, the pancreatic lipase activity in the HDJ was $48 \mathrm{U} / \mathrm{mL}$, and the bile salt concentration in the HDJ was $0.230 \mathrm{mM}$. Ascorbic acid was analyzed by the method described by Lykkesfeldt et al. by ion chromatography followed by electrochemical detection [31], and approximately 0.3 ppm was detected in both HGJ and HDJ. $\mathrm{Ca}^{2+}$ was analyzed by an ion chromatograph couples with UV-vis according to Fredrikson et al. [32], and was found to be present in HGJ at $35 \mathrm{ppm}$ and in HDJ at $16 \mathrm{ppm}$.

\subsection{Marine Oils}

Refined cod liver oil (Gadus morhua), without added antioxidants, was supplied by Lýsi hf (Reykjavík, Iceland). Unrefined algae oil from Schizochytrium sp. called Life's DHA S35-CO100 was supplied from DSM (Basel, Switzerland). Unrefined krill oil from Antarctic krill (Euphausia superba) called Superba $^{\mathrm{TM}}$ Krill Oil (Aker Biomarine Antarctic AS, Oslo, Norway) was provided by Sanpharm AB (Gothenburg, Sweden). The LC $n-3$ PUFA profile of the oils, \% as reported by Jónsdóttir et al. and according to the manufacturers specification [33], and quantitatively (mg FAME/g oil) measured in-house according to Cavonius et al. [34], can be found in the supplementary material (Table S1).

\subsection{In Vitro Digestion with Human Digests}

The three marine oils were digested in vitro in a static three-step digestion model, using the human digestive fluids. The model is based on the standardized InfoGest protocol with minor modifications [30]. The recommended daily intake (RDI) for supplemental oils are based on the consumption of EPA and DHA, and therefore the dose of each oil was normalized to its EPA and DHA content before the simulated GI digestion. For each oil, an amount providing $5 \mathrm{mg}$ total LC n-3 PUFA, i.e., EPA+DHA, was used, which corresponds to $250 \mathrm{mg}$ on a human level. Water was added to achieve samples of the same volume. In control digestions, oils were omitted and only water was used. In short, digestion was performed in darkness and the oil-water mixture was digested by one volume saliva, followed by HGJ addition $\left(1: 1, \mathrm{pH} 6,37^{\circ} \mathrm{C}, 50 \mathrm{rpm}, 120 \mathrm{~min}\right)$, including adjustment of $\mathrm{pH}$ to $\mathrm{pH} 3$ after $60 \mathrm{~min}$. Intestinal digestion was performed by the addition of HDJ (1:1, pH 7, $\left.37^{\circ} \mathrm{C}, 250 \mathrm{rpm}, 90 \mathrm{~min}\right)$. Digested samples were flushed with $\mathrm{N}_{2}$ gas $(15 \mathrm{~s})$ and stored in $-80{ }^{\circ} \mathrm{C}$ until aldehyde analysis and cell experiments.

\subsection{Cell Line}

Caco-2 cells (HTB-37), passage 19, were obtained from the American Type Culture Collection (Rockville, MD, USA). The cells were cultured in an incubator at $37^{\circ} \mathrm{C} / 5 \% \mathrm{CO}_{2} / 95 \%$ humidified air. The medium used was EMEM (FBS; $10 \%)$ supplemented with Normocin ${ }^{\mathrm{TM}}(0.2 \%$; Invivogen, San Diego, CA, USA). The medium was replaced every second or third day and passaging of cells was done at approximately 80\% confluence. At passage 29-37, the cells were seeded in 12-well plates with Transwell ${ }^{\circledR}$ polycarbonate inserts $(0.4 \mu \mathrm{m}$; Corning, San Francisco, MA, USA) at 60,000 cells /insert or without inserts (CellBiND ${ }^{\circledR}$, polystyrene; Corning, Kennebunk, ME, USA) at 200,000 cells/well. All of the experiments were carried out 14 days post-seeding. 


\subsection{Cell Experiments}

Cells (on inserts) were treated with in vitro digested marine oils and control digests (without oil), diluted 1:1 in the apical medium. The apical medium was added $(0.5 \mathrm{~mL})$ to the cells $24 \mathrm{~h}$ prior to the experiments to let the cells produce endogenous trypsin inhibitor. At the time of the experiment, $0.25 \mathrm{~mL}$ of the apical medium was replaced by $0.25 \mathrm{~mL}$ of the digests and were then left in the incubator for $2 \mathrm{~h}\left(37^{\circ} \mathrm{C}\right)$. Controls with only medium were included, as well as standards with MDA in water and HHE in DMSO (DMSO at 0.01\%), corresponding to the highest levels detected in digests; 16.6 and $2.8 \mu \mathrm{M}$, respectively. Standards were as digests diluted 1:1 in the apical medium, hence exposure of cells to MDA and HHE were 8.3 and $1.4 \mu \mathrm{M}$, respectively. From here on, these levels of MDA and HHE are referred to as "low" levels. To separately study the toxicity of the aldehydes at different levels, an experiment with cells in wells without inserts was performed. MDA levels tested were 8.3, 45, and $90 \mu \mathrm{M}$; HHE levels tested were 1.4, 45, and $90 \mu \mathrm{M}$. A mix (1:1) of the two aldehydes was also studied at (1) $45 \mu \mathrm{M}$ each of MDA and HHE; (2) $22.5 \mu \mathrm{M}$ each of MDA and HHE, and (3) $4.15 \mu \mathrm{M}$ MDA and $0.7 \mu \mathrm{M} \mathrm{HHE}$, to test combined, e.g., synergistic, effects. $90 \mu \mathrm{M}$ of the individual aldehydes and $45 \mu \mathrm{M}$ of each in a mix are from here on referred to as "high" levels. The highest aldehyde levels are in the same range, as previously used by Awada et al. [10], the levels in the middle are half of the highest levels, and in the same range as used by Alghazeer et al. [35]. Minimum Essential Medium Eagle, HEPES modification powder (14.2 g/L; Sigma-Aldrich, Schnelldorf, Germany) was used to be able to achieve high MDA concentrations without dilution, and mixed (1:1) with the ordinary medium that was used when studying the mixed effect of MDA and HHE. After the $2 \mathrm{~h}$ of incubation, the medium was aspirated and the cells were washed in PBS and lysed.

\subsection{Harvesting of Caco-2 Cells and Protein Analysis}

The medium was removed and the cells were washed in PBS prior to harvest. The basal medium was collected and the cells were lysed in RIPA (Sigma-Aldrich, Schnelldorf, Germany) with EDTA-free Pierce $^{\mathrm{TM}}$ Protease and Phosphatase inhibitor (Thermo Fisher Scientific, Waltham, MA, USA). Total cellular protein content was measured by Pierce ${ }^{\mathrm{TM}} \mathrm{BCA}$ Protein Assay Kit (Thermo Fisher Scientific, Waltham, MA, USA), following the instructions from the manufacturer. From the total protein content (which is proportional to cell number), cell viability/survival was estimated.

\subsection{Analysis of Peroxide Value (PV) and Aldehydes (HHE \& MDA)}

Peroxide value $(\mathrm{PV})$ was analysed prior to digestion in the crude oils by thiocyanate and ferric iron complexation, according to Undeland et al. [36].

HHE and MDA were analyzed, as described by Tullberg et al. [8]. Briefly, digests and basolateral media were acidified to precipitate proteins, followed by DNPH-derivatization and dichloromethane extraction. Samples were evaporated and re-suspended in $\mathrm{MeOH}$, aldehydes were then determined in digests by detection on LC/APCI-MS (Agilent 1260 HPLC coupled with Agilent 6120 quadrupole; Agilent Technologies, Waldbron, Germany) in negative mode, using external standards for MDA and HHE. Analysis of the data was carried out using the software Agilent ChemStation (Agilent Technologies, Böblingen, Germany).

\subsection{Human Cell Stress Array Analysis}

The Human Cell Stress Array Kit (Bio-techne, Minneapolis, MN, USA) was used according to manufacturer's protocol. Briefly, membranes coated with 26 capture antibodies were blocked $(1 \mathrm{~h}$, RT). The blocking buffer was aspirated and the samples were adjusted by total cellular protein content were added (105 $\mu \mathrm{g}$ total protein; $n=3)$ together with a biotinylated antibody cocktail for detection (overnight, $130 \mathrm{rpm}, 4{ }^{\circ} \mathrm{C}$ ). Membranes were then washed in a wash buffer (10 min, repeated three times). Streptavidin-conjugated horseradish peroxidase (HRP) was added to the membranes (30 min, RT), and membranes were again washed (10 min, repeated 3 times). After the last washing step, 
a reaction mixture containing hydrogen peroxide and luminol (1:1) was added to the membranes, and was instantly analyzed with a detection system for chemiluminescence (Chemidoc XRS+, Bio-Rad), followed by software analysis of the images by ImageLab (Bio-Rad). See Table 1 for the specific analytes detected.

Table 1. Proteins detected by the Human Cell Stress Array Kit.

\begin{tabular}{|c|c|c|c|}
\hline $\mathrm{Nr}$ & Analyte & $\mathrm{Nr}$ & Analyte \\
\hline 1 & ADAMTS1 & 14 & IDO \\
\hline 2 & Bcl-2 & 15 & $\begin{array}{l}\text { Phospho-JNK PAN } \\
\text { (T183/Y185) }\end{array}$ \\
\hline 3 & Carbonic Anhydrase IX & 16 & NFkB1 \\
\hline 4 & Cited-2 & 17 & p21/CIP1 \\
\hline 5 & COX-2 & 18 & p27 \\
\hline 6 & Cytochrome C (Cyt C) & 19 & $\begin{array}{l}\text { Phospho-p38a } \\
\text { (T180/Y182) }\end{array}$ \\
\hline 7 & Dickkopf-4 (Dkk-4) & 20 & Phospho-p53 (S46) \\
\hline 8 & $\begin{array}{l}\text { Fatty acid-binding } \\
\text { protein } 1 \text { (FABP-1) }\end{array}$ & 21 & Paraoxonase-1 (PON-1) \\
\hline 9 & HIF-1a & 22 & Paraoxonase-2 (PON-2) \\
\hline 10 & HIF-2a & 23 & Paraoxonase-3 (PON-3) \\
\hline 11 & $\begin{array}{c}\text { Phospho-HSP27 } \\
\text { (S78/S82) }\end{array}$ & 24 & Thioredoxin-1 (Trx-1) \\
\hline 12 & $\begin{array}{l}\text { Heat Shock Protein-60 } \\
\text { (HSP-60) }\end{array}$ & 25 & $\begin{array}{c}\text { Deacetylase Sirtuin } 2 \\
\text { (SIRT2) }\end{array}$ \\
\hline 13 & $\begin{array}{l}\text { Heat Shock Protein-70 } \\
\text { (HSP-70) }\end{array}$ & 26 & $\begin{array}{l}\text { Superoxide dismutase } \\
2 \text { (SOD2) }\end{array}$ \\
\hline
\end{tabular}

\subsection{Statistics}

Calculated values are presented as mean values \pm standard deviation $(\mathrm{SD} ; n=3)$ or when $n=2$ as mean values $\pm(\max -\min ) / 2$. Digestion of oils with subsequent cell experiments were made in triplicates and repeated at three occasions, human stress arrays were done in duplicates and repeated 2-3 times. The significance of the difference between treatment and control was analyzed by Student's two-tailed, unpaired $t$ test, and treatments were compared by a one- or two-way analysis of variance (ANOVA; Microsoft Office Excel, 2013), followed by treatment to treatment $t$ test as above, whenever applicable. Differences were considered significant at $p \leq 0.05$. Significant levels are denoted in the graphs and tables when applicable; ${ }^{*}=p \leq 0.05,{ }^{* *}=p \leq 0.01,{ }^{* * *}=p \leq 0.001$.

\section{Results}

\subsection{MDA and HHE Formation during In Vitro Digestion with Human Digestive Fluids}

The initial aldehyde levels prior to digesteion were $0.013 \pm 0.01,0.11 \pm 0.05$, and $0.38 \pm 0.14$ $\mu \mathrm{M}$, for MDA, and $0.005 \pm 0.009,0.17 \pm 0.02$, and $0.04 \pm 0.007 \mu \mathrm{M}$ for HHE in the algae-, cod liverand krill oil, respectively. The corresponding peroxide values (PV) in the crude oils were $0.18 \pm 0.05$ in algae-, $1.48 \pm 0.06$ in cod liver- and $1.00 \pm 0.30(\mathrm{mmol} / \mathrm{kg}$ oil) in the $\mathrm{krill}$ oil. According to the PV and HHE measurement, the cod liver oil was the most oxidized oil initially, however the krill oil contained a higher initial concentration of MDA. The aldehydes MDA and HHE both increased from start $(t=0 \mathrm{~min})$ to end $(t=210 \mathrm{~min})$ of the in vitro digestion. The levels of MDA and HHE detected in the digests were approximately 4 and 7-20 times higher in the cod liver oil as compared to the other oils, respectively (Table 2). 
Table 2. Detected levels $(\mu \mathrm{M})$ of 4-hydroxy-2-hexenal (HHE) and malondialdehyde (MDA) in in vitro digests $(t=210 \mathrm{~min}$ ) using human digestive fluids. Data are shown as mean \pm standard deviation (SD), $n=3$.

\begin{tabular}{ccc}
\hline Marine Oil & MDA $\mu \mathbf{M} \pm$ SD & HHE $\mu$ M \pm SD \\
\hline Algae oil & $4.45 \pm 1.81$ & $0.13 \pm 0.039$ \\
Cod liver oil & $16.6 \pm 7.74$ & $2.77 \pm 2.66$ \\
Krill oil & $4.29 \pm 0.70$ & $0.38 \pm 0.061$ \\
\hline
\end{tabular}

\subsection{Cell Survival Was Not Significantly Affected by Either Oil Digests or HHE and MDA}

There was no significant effect of digested oils on cell survival after $2 \mathrm{~h}$ of incubation and 22 additional hours with fresh medium (Figure 1). In a dose-response experiment with the oxidation products MDA and HHE, similar results were achieved with no adverse effect on cell viability (Figure 2). A minor increase was seen in protein levels when adding $45 \mu \mathrm{M}$ of HHE, however this effect was within 2 SD:s and thus natural variation.

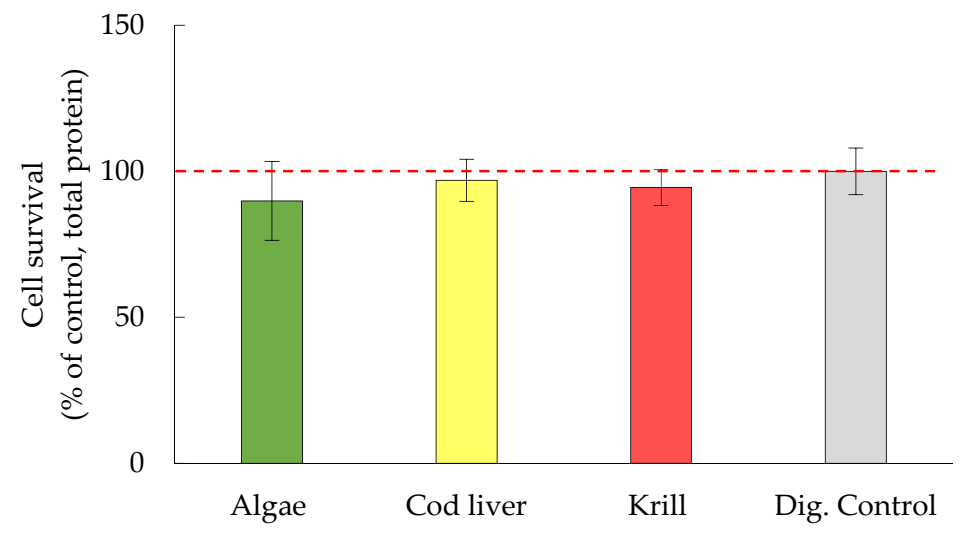

Figure 1. Cell survival estimated from the change in total protein level between untreated and treated cells, data are shown as mean $\% \pm(\max -\min ) / 2, n=2$. Dig. Control = digests from digestion of only water.

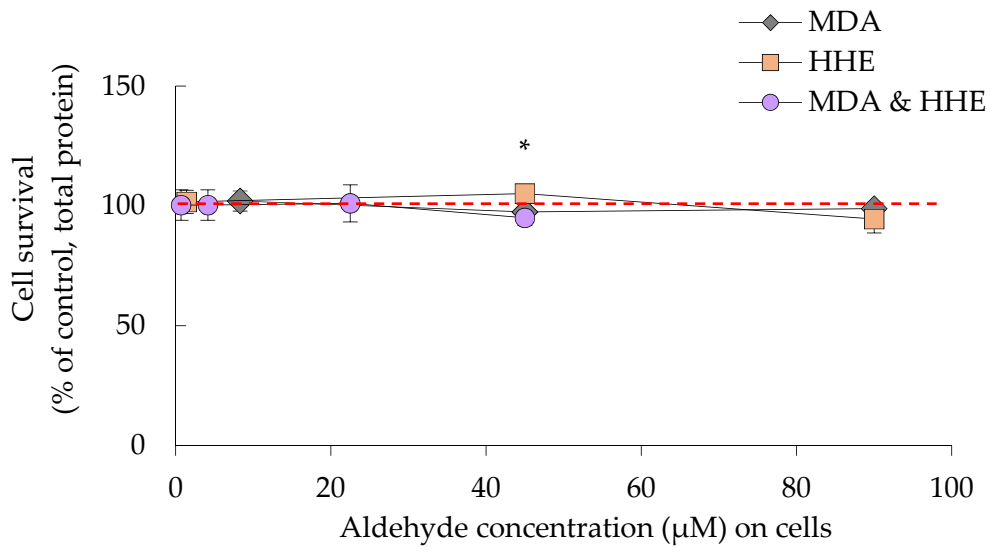

Figure 2. Cell survival in the presence of increasing concentrations of the aldehydes malondialdehyde (MDA) and 4-hydroxy-2-hexenal (HHE), data are shown as means $\pm(\max -\min ) / 2, n=2$, or $n=4$ for the lowest concentrations of MDA $(8.3 \mu \mathrm{M})$ and HHE $(1.4 \mu \mathrm{M})$. Significant difference $(p \leq 0.05)$. MDA and HHE is the combination of both aldehydes, at the lowest concentrations, $4.15 \mu \mathrm{M}$ MDA and 0.7 $\mu$ M HHE. ${ }^{*}=p \leq 0.05$. 


\subsection{Cellular Levels of HSP-70 and Trx-1 Were Decreased in the Presence of Digested Marine Oils}

All of the digested oils significantly decreased the expression of HSP-70 and Trx-1 ( $p \leq 0.001)$, Figure 3. In addition, SOD2 levels were significantly lowered in the presence of algae and cod liver oil digests. Krill oil digests did not significantly affect SOD2 levels. HSP-70, Trx-1 and SOD2 are all a part of the anti-oxidative stress defense and are generally increased when the cells are exposed to oxidative stress $[37,38]$. HSP-70 is a chaperone protein that reduces oxidative damage by binding to proteins, which prevents unfolding and aggregation. Trx-1 is an oxidoreductase facilitating the reduction of oxidized proteins and SOD2 is a superoxide dismutase that eliminates superoxide radicals. The levels of HSP-60, coming from the same family as HSP-70, was significantly lowered in the presence of digested algae and krill oil, however not by digested cod liver oil.

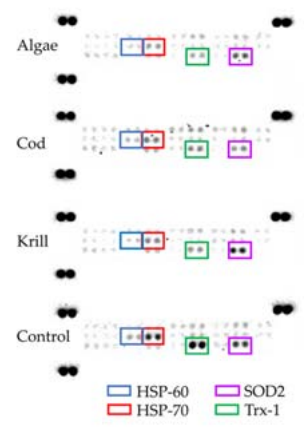

(a)

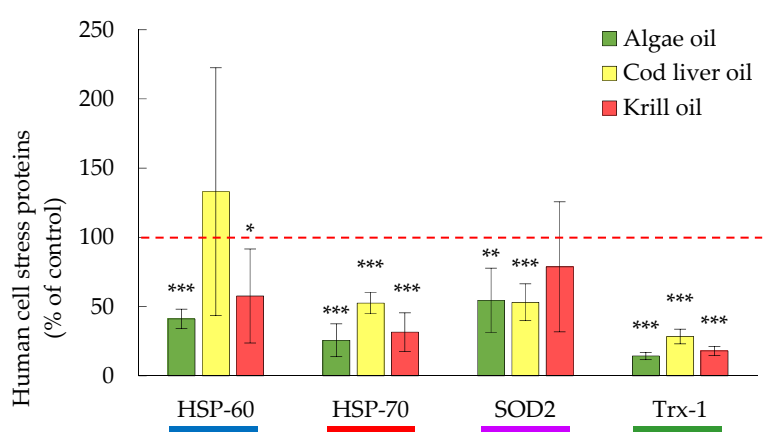

(b)

Figure 3. (a) Representative membranes showing the expression of human stress-related proteins (Proteome profiler ${ }^{\mathrm{TM}}$ arrays) in the presence of marine oils digested by human GI fluids.; (b) Bar graph representation of data for pooled triplicates of lysates $\pm \mathrm{SD}, n=3 .{ }^{*}=p \leq 0.05,{ }^{* *}=p \leq 0.01,{ }^{* * *}=p \leq$ 0.005. HSP-60= Heat Shock Protein-60; HSP-70= Heat Shock Protein-70; SOD2= Superoxide dismutase 2; Trx-1= Thioredoxin-1.

\subsection{Cellular Hsp-70 and Trx-1 Levels Were Not Affected by Low MDA and HHE Levels (8.3 and 1.4 $\mu \mathrm{M}$ )}

Low concentrations of MDA $(8.3 \mu \mathrm{M})$ and HHE $(1.4 \mu \mathrm{M})$, corresponding to the highest aldehyde levels in the marine oil digests, which the cells were exposed to, did not, or did only slightly, affect the cellular levels of HSP-70, TRX-1, SOD2, Figure 4. In addition, the HSP-70 family member, HSP-60, decreased significantly $(p=0.043)$ in the presence of low level HHE $(1.4 \mu \mathrm{M})$.

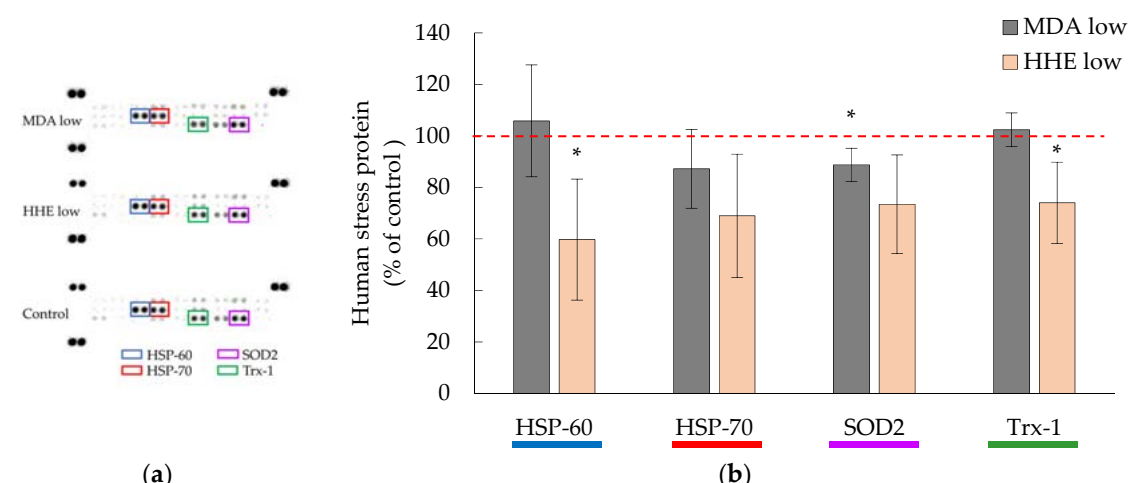

(a)

(b)

Figure 4. (a) Representative membrane showing the expression of human stress-related proteins (Proteome profiler ${ }^{\mathrm{TM}}$ arrays) in the presence of "low" aldehyde levels, $1.4 \mu \mathrm{M}$ 4-hydroxy-2-hexenal (HHE) and $8.3 \mu \mathrm{M}$ malondialdehyde (MDA), i.e., the levels found in cod liver oil digests; (b) Bar graph of the data for pooled triplicates of lysates $\pm(\max -\min ) / 2, n=2$. ${ }^{*}=p \leq 0.05$. HSP-60= Heat Shock Protein-60; HSP-70= Heat Shock Protein-70; SOD2= Superoxide dismutase 2; Trx-1= Thioredoxin-1. 


\subsection{High Levels (90 $\mu \mathrm{M})$ of MDA and HHE Did Not Affect the Cellular Levels of HSP-70 and Trx-1}

High concentrations of aldehydes $(90 \mu \mathrm{M})$, did not significantly affect the cellular levels of HSP-70 and Trx-1, Figure 5. The stress proteins detected were even closer to $100 \%$ of the control as compared to the addition of low aldehyde levels to the cells, but HSP-60 significantly increased in the presence of high MDA concentrations ( $p=0.026$ ). Testing a combination of MDA and HHE, both at $45 \mu \mathrm{M}$, the result was a combined effect that was similar to the presence of isolated aldehydes at $90 \mu \mathrm{M}$. HSP-60 however, increased ( $p=0.0054$, MDA \& HHE) when compared to control, and Trx-1 was significantly lower than the control when cells were exposed to the MDA and HHE mix $(p=0.032)$.

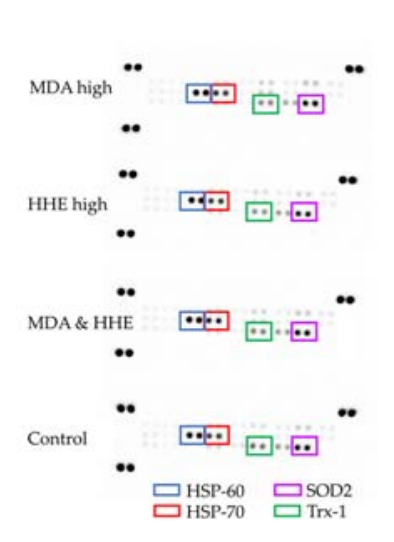

(a)

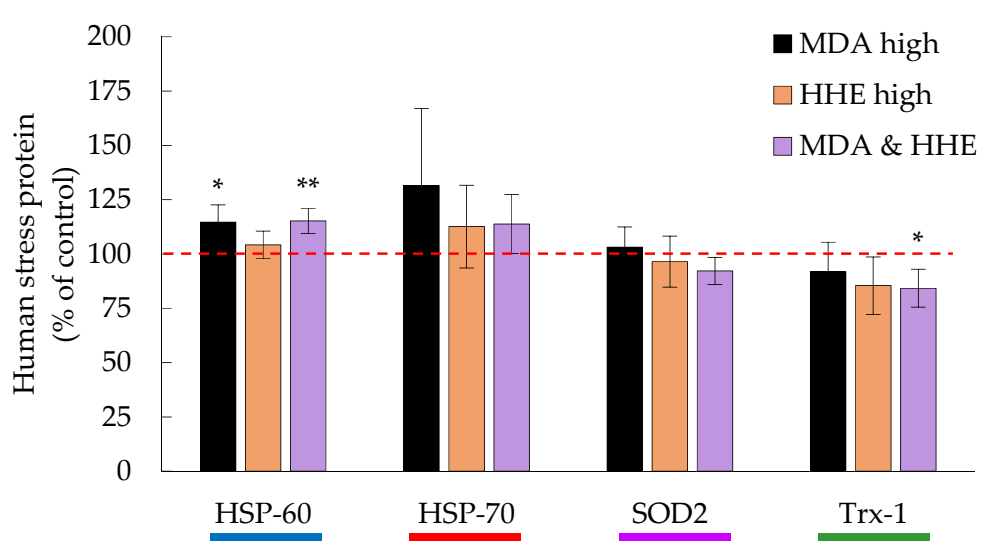

(b)

Figure 5. (a) A representative membrane showing the expression of human stress-related proteins (Proteome profiler ${ }^{\mathrm{TM}}$ arrays) in the presence of high aldehyde levels (90 $\mu \mathrm{M}$ MDA; $90 \mu \mathrm{M} \mathrm{HHE} ; 45 \mu \mathrm{M}$ MDA \& HHE); (b) Bar graph of the data for pooled triplicates of lysates of cells in the presence of MDA $(90 \mu \mathrm{M}), \mathrm{HHE}(90 \mu \mathrm{M})$ and a mix of MDA and HHE (45 $\mu \mathrm{M}$ each), data are shown as means \pm ( $\max$ $-\min ) / 2, n=2 .{ }^{*}=p \leq 0.05,{ }^{* *}=p \leq 0.01 . \mathrm{MDA}=$ malondialdehyde; HHE= 4-hydroxy-2-hexenal; HSP-60= Heat Shock Protein-60; HSP-70= Heat Shock Protein-70; SOD2= Superoxide dismutase 2; Trx-1= Thioredoxin-1.

\subsection{Levels of MDA and HHE on the Basal Side of the Epithelium}

High concentrations of MDA and HHE were found in the basal medium after the incubation of Caco-2 cells with the oil digests $(1.4,2.1$ and $0.8 \mu \mathrm{M}$ MDA; $0.09,0.2$ and $0.06 \mu \mathrm{M}$ HHE for algae, cod liver, and krill oil, respectively). The absolute amounts (nmol) in the apical versus the basal medium are presented in Figure 6 . The medium with the algae oil digests contained significantly $(p \leq 0.05)$ more MDA and HHE in the basal medium when compared to the apical medium. With the present experimental setup, we do not know if, or how much of, MDA and HHE that was actually transported across the intestinal epithelium. The decomposition of the digested oils is expected to be extensive, due to the elevated temperature $\left(\mathrm{T}=37^{\circ} \mathrm{C}\right)$, during the $2 \mathrm{~h}$ incubation time. This is expected to give increasing levels of aldehydes in the apical medium, and therefore a ratio of the basal concentration of MDA and HHE to the added sample concentration of MDA and HHE will not give an accurate measure of the transport. Thus, the bioavailability cannot be correctly estimated. Awada et al., who used deuterium labelling, estimated the basolateral transport of HHE in Caco-2/TC7 cells, which resulted in approximately $0.2 \%$ HHE transfer $(100 \mu \mathrm{M}, 24 \mathrm{~h})$ [10]. This gives an indication of in which magnitude we should expect to find the transport. When we conducted a transport experiment with pure HHE, we found that HHE was transported across the epithelium at $1.14 \%$ when incubated with $1.4 \mu \mathrm{M}$ HHE for $2 \mathrm{~h}$. Corresponding data was $10.6 \%$ when using the lower concentration of HHE $(0.65 \mu \mathrm{M}, 2 \mathrm{~h})$, Table 3. 


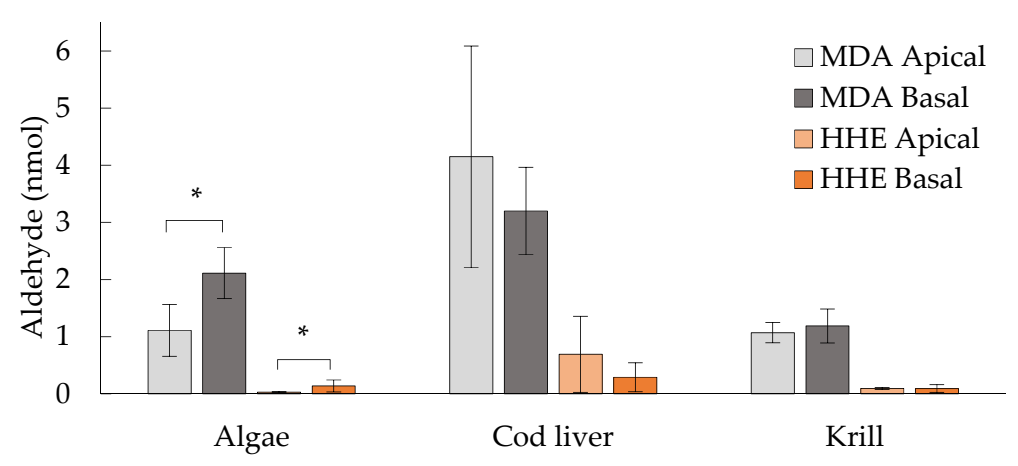

Figure 6. Aldehyde (nmol) added to the apical medium and detected in the basal medium of Caco-2 cells after incubation $(t=2 \mathrm{~h})$. Data are shown as means \pm standard deviation (SD), $n=3 .^{*}=p \leq 0.05$. $\mathrm{MDA}=$ malondialdehyde; $\mathrm{HHE}=4$-hydroxy-2-hexenal.

Table 3. Absolute quantity of 4-hydroxy-2-hexenal (HHE; nmol) present in the apical and basal medium $(\mathrm{BM}), n=3$.

\begin{tabular}{cc}
\hline HHE (nmol) Added & HHE (nmol), BM \\
\hline 0.7 & $0.0080 \pm 0.0042$ \\
0.0325 & $0.0035 \pm 0.0011$ \\
\hline
\end{tabular}

\section{Discussion}

\subsection{Oxidation of the Oils during In Vitro Digestion}

Both MDA and HHE levels increased during in vitro digestion with human digestive fluids. These results are in agreement with results from studies where cod liver oil and salmon were subjected to in vitro digestion models, in which enzymes and bile have been of porcine or other animal origin $[9,39,40]$. Increase in aldehyde formation during digestion was also observed in our previous study, when digesting cod liver oil with human GI fluids [8].

\subsection{Human Digests of Marine Oils and the Aldehydes MDA and HHE Had No Adverse Effect on the Epithelium}

From these studies, we can conclude that the digested oils and their MDA/HHE content did not have a negative impact on the cells. The absence of effects of pure MDA and HHE (1.4-90 $\mu \mathrm{M})$ on cell survival is supported by Awada et al. [10], in which no effect in TEER after incubating Caco-2 and T27 cells with similar levels of aldehydes $(24 \mathrm{~h}, 0-100 \mu \mathrm{M})$ was observed. On the contrary, proteins associated with oxidative damage (Trx-1 and HSP-70) were down-regulated in the presence of all three digested marine oils, suggesting that the cells actually were experiencing less oxidative stress than in the absence of the digested oils. In addition, pure MDA and HHE, corresponding to the concentrations found in the oil digests, did not increase oxidative stress markers in the cells, HHE even significantly reduced the levels of Trx-1 in the cells, indicating that MDA and HHE had no harmful effect at the levels found after in vitro digestion of the three marine oils with human GI fluids. Hence, the lipid oxidation taking place during in vitro GI digestion in this study was not associated with harmful effects in human intestinal cells. Although it is not directly comparable with studies of digests in intestinal cell models, HHE has been shown to promote Nrf2 activation in HUVEC cells [41], and also, oxidized EPA has been shown to inhibit NF- $\mathrm{kB}$ activation in murine aortic endothelial cells [42]. In addition, a recent review by Roy et al. suggests that ROS play an important role for cellular redox homeostasis [43]. All of these data are in line with our findings. However, there are also some studies with digested marine oils showing opposite results to ours regarding lipid oxidation and effects on Caco-2 cells $[7,10]$. Different outcomes may in several cases be a direct cause of different experimental setups, such as exposing intestinal cells to undigested oils, exposing other cell types than intestinal cells to GI digests, 
using oils with a higher oxidation degree, using longer incubation time, or feeding a cell type of non-intestinal origin with oils. Even though we did not identify the adverse effects of MDA and HHE on the intestinal level, there may be potentially harmful systemic effects of lipid oxidation products, e.g., MDA protein adducts have been implicated in coronary artery disease development [44].

\subsection{Comparison of the Different Marine Oils}

In the crude oils, the concentration of EPA plus DHA was in the following order: algae $>$ krill > cod liver oil. Digests with cod liver oil therefore contained the highest amount $(\mathrm{mg} / \mathrm{mL})$ of total oil per digest when compared to the other oils (10\% more oil than krill oil, 50\% more than algae oil). Algae oil contained mainly DHA, while the other two oils contained ratios between EPA and DHA that were 0.8 and 2.0 for cod liver oil and krill oil, respectively. The krill oil is unique in that it contains high levels of phospholipids and the antioxidant astaxhantin. The stability of the EPA/DHA-normalized samples differed between the oils during the GI digestion, and the cod liver oil was the one most oxidized after completed digestion (highest [MDA] and [HHE]). In the comparison of the different oil digests, blanks with pure digests without added oil, were always included as controls.

When comparing the effects of the digested oils on HSP-70 and Trx-1 levels, a significant difference between the cod liver oil and the other two oils was observed; but no significant difference was observed between algae and krill oil. Digested cod liver oil did not significantly affect HSP-60, while both the digested algae and krill oils had a reducing effect; indicating that a low oxidation degree, as in the algae and krill oils after digestion, could have a HSP-60 decreasing effect. However, this effect could also be due to the protective effects from the natural antioxidants in the algae and krill oils [24-26].

Krill oil digests did not significantly reduce the levels of the superoxide dismutase SOD2 as the other oils did. Krill oil digests also had a lower HHE to MDA ratio than cod liver and algae oil digests, but if there is a specific effect of HHE on the down-regulation of SOD2 levels is not known. Free fatty acids (FFA) extracted from krill oil was previously found to inhibit cell growth and induce apoptosis when added in undigested form to HCT-15, SW-480, and Caco-2 cells [45]. Our digests contain a mixture of FFA, as well as partially hydrolyzed TAG and phospholipids, but indeed the FFA could play a specific role. In another study, undigested whole krill oil was also found to have anti-inflammatory action, thus reducing the pro-inflammatory cytokines IL-8 and TNF $\alpha$ that was produced by Caco- 2 and HT29 cells [46]. In a human trial, krill oil was found to have a positive effect on intestinal endothelial function, giving a mean EndoPAT Reactive Hyperemia Index of 2.16 after 17 weeks of supplementation, and the ingestion of krill oil also increased the serum levels of high-density lipoprotein [47], however it is not known whether these results had any connection to formation of lipid oxidation products in the krill oil during digestion.

In general, our results from comparing the three different oil digests indicate that krill oil, cod liver oil, and algae oil, have similar characteristics in regards to not being cytotoxic or stress-promoting to intestinal epithelial cells. The oil digest with the most reducing effect on HSP-60, HSP-70, and Trx-1 was that from algae oil. Algae oil differed from the other oils in that it had a different FA profile with a high content of DHA, a low content of the other FA, and also another antioxidant profile. Whether these factors played a role in reducing the oxidative stress response requires future work.

\section{Conclusions}

Exposing the Caco-2 cells with digests of marine oils and pure aldehydes did not affect cell survival. All of the digests significantly reduced the cellular expression of the human cellular stress proteins HSP-70 and Trx-1, indicating that the cells were experiencing less oxidative stress. Exposure $(t=2 \mathrm{~h})$ to pure MDA at the same level that was present in the digests $(8.3 \mu \mathrm{M})$ significantly lowered the expression of SOD2. Corresponding exposure of pure HHE at the level found in the digests $(1.4 \mu \mathrm{M})$ decreased expression of HSP-60 and Trx-1. A mix of MDA and HHE (45 $\mu \mathrm{M}$ of each) significantly diminished the cellular expression of Trx-1, however, at high levels $(90 \mu \mathrm{M})$ there was no change 
in Trx-1 expression. Altogether, the present aldehyde concentrations, relevant to aldehyde levels formed in vivo, did not increase the levels of the investigated stress-related proteins, indicating that physiological levels of these aldehydes may not induce intestinal cell stress.

Supplementary Materials: The following are available online at www.mdpi.com/2072-6643/9/11/1213/s1, Table S1: Amounts of EPA and DHA of algae oil, cod liver oil, and krill oil.

Acknowledgments: This study was funded by the Swedish Council for Environment, Agricultural Sciences and Spatial Planning, Formas (Grant no. 222-2012-1331).

Author Contributions: C.T., N.S. and I.U. conceived and designed the experiments; C.T. performed the experiments; C.T. and N.S. analyzed the data; N.S. contributed with expertise in cell studies and took an active part in the writing process; G.V. contributed with collection of human digests, design of in vitro digestion model and support during the writing process; I.U. contributed with expertise in the field of marine oils and lipid oxidation, and contributed with support during the writing process; C.T. was responsible for writing the paper.

Conflicts of Interest: The authors declare no conflict of interest.

\section{References}

1. Lavie, C.J.; Milani, R.V.; Mehra, M.R.; Ventura, H.O. Omega-3 polyunsaturated fatty acids and cardiovascular diseases. J. Am. Coll. Cardiol. 2009, 54, 585-594. [CrossRef] [PubMed]

2. Delgado-Lista, J.; Perez-Martinez, P.; Lopez-Miranda, J.; Perez-Jimenez, F. Long chain omega-3 fatty acids and cardiovascular disease: A systematic review. Br. J. Nutr. 2012, 107 (Suppl. 2), S201-S213. [CrossRef] [PubMed]

3. Kanner, J.; Lapidot, T. The stomach as a bioreactor: Dietary lipid peroxidation in the gastric fluid and the effects of plant-derived antioxidants. Free Radic. Biol. Med. 2001, 31, 1388-1395. [CrossRef]

4. Turner, R.; McLean, C.H.; Silvers, K.M. Are the health benefits of fish oils limited by products of oxidation? Nutr. Res. Rev. 2006, 19, 53-62. [CrossRef] [PubMed]

5. Albert, B.B.; Cameron-Smith, D.; Hofman, P.L.; Cutfield, W.S. Oxidation of marine omega-3 supplements and human health. Biomed. Res. Int. 2013, 2013, 464921. [CrossRef] [PubMed]

6. Kristinova, V.; Storrø, I.; Rustad, T. Influence of human gastric juice on oxidation of marine lipids-In vitro study. Food Chem. 2013, 141, 3859-3871. [CrossRef] [PubMed]

7. Maestre, R.; Douglass, J.D.; Kodukula, S.; Medina, I.; Storch, J. Alterations in the intestinal assimilation of oxidized pufas are ameliorated by a polyphenol-rich grape seed extract in an in vitro model and caco- 2 cells. J. Nutr. 2013, 143, 295-301. [CrossRef] [PubMed]

8. Tullberg, C.; Larsson, K.; Carlsson, N.G.; Comi, I.; Scheers, N.; Vegarud, G.; Undeland, I. Formation of reactive aldehydes (MDA, HHE, HNE) during the digestion of cod liver oil: Comparison of human and porcine in vitro digestion models. Food Funct. 2016, 7, 1401-1412. [CrossRef] [PubMed]

9. Larsson, K.; Harrysson, H.; Havenaar, R.; Alminger, M.; Undeland, I. Formation of malondialdehyde (MDA), 4-hydroxy-2-hexenal (HHE) and 4-hydroxy-2-nonenal (HHE) in fish and fish oil during dynamic gastrointestinal in vitro digestion. Food Funct. 2016, 7, 1176-1187. [CrossRef] [PubMed]

10. Awada, M.; Soulage, C.O.; Meynier, A.; Debard, C.; Plaisancie, P.; Benoit, B.; Picard, G.; Loizon, E.; Chauvin, M.A.; Estienne, M.; et al. Dietary oxidized n-3 PUFA induce oxidative stress and inflammation: Role of intestinal absorption of 4-HHE and reactivity in intestinal cells. J. Lipid Res. 2012, 53, 2069-2080. [CrossRef] [PubMed]

11. Gutteridge, J.M. Free-radical damage to lipids, amino acids, carbohydrates and nucleic acids determined by thiobarbituric acid reactivity. Int. J. Biochem. 1982, 14, 649-653. [CrossRef]

12. Frankel, E.N.; Neff, W.E. Formation of malonaldehyde from lipid oxidation-products. Biochim. Biophys. Acta 1983, 754, 264-270. [CrossRef]

13. Esterbauer, H.; Schaur, R.J.; Zollner, H. Chemistry and biochemistry of 4-hydroxynonenal, malonaldehyde and related aldehydes. Free Radic. Biol. Med. 1991, 11, 81-128. [CrossRef]

14. Ayala, A.; Muñoz, M.F.; Argüelles, S. Lipid peroxidation: Production, metabolism, and signaling mechanisms of malondialdehyde and 4-hydroxy-2-nonenal. Oxid. Med. Cell. Longev. 2014, 2014, 31. [CrossRef] [PubMed]

15. Del Rio, D.; Stewart, A.J.; Pellegrini, N. A review of recent studies on malondialdehyde as toxic molecule and biological marker of oxidative stress. Nutr. Metab. Cardiovasc. Dis. 2005, 15, 316-328. [CrossRef] [PubMed] 
16. Uchida, K. Role of reactive aldehyde in cardiovascular diseases. Free Radic. Biol. Med. 2000, 28, $1685-1696$. [CrossRef]

17. LoPachin, R.M.; Gavin, T. Molecular mechanisms of aldehyde toxicity: A chemical perspective. Chem. Res. Toxicol. 2014, 27, 1081-1091. [CrossRef] [PubMed]

18. Van Kuijk, F.J.; Holte, L.L.; Dratz, E.A. 4-hydroxyhexenal: A lipid peroxidation product derived from oxidized docosahexaenoic acid. Biochim. Biophys. Acta 1990, 1043, 116-118. [CrossRef]

19. Guichardant, M.; Bacot, S.; Moliere, P.; Lagarde, M. Hydroxy-alkenals from the peroxidation of $n-3$ and n-6 fatty acids and urinary metabolites. Prostaglandins Leukot. Essent. Fat. Acids 2006, 75, 179-182. [CrossRef] [PubMed]

20. Calder, P.C. Omega-3 polyunsaturated fatty acids and inflammatory processes: Nutrition or pharmacology? Br. J. Clin. Pharmacol. 2013, 75, 645-662. [CrossRef] [PubMed]

21. Awada, M.; Meynier, A.; Soulage, C.O.; Hadji, L.; Geloen, A.; Viau, M.; Ribourg, L.; Benoit, B.; Debard, C.; Guichardant, M.; et al. N-3 PUFA added to high-fat diets affect differently adiposity and inflammation when carried by phospholipids or triacylglycerols in mice. Nutr. Metab. (Lond.) 2013, 10, 23. [CrossRef] [PubMed]

22. Soni, N.K.; Ross, A.B.; Scheers, N.; Savolainen, O.I.; Nookaew, I.; Gabrielsson, B.G.; Sandberg, A.S. Splenic immune response is down-regulated in C57BL/6 $\mathrm{J}$ mice fed eicosapentaenoic acid and docosahexaenoic acid enriched high fat diet. Nutrients 2017, 9, 50. [CrossRef] [PubMed]

23. Cicero, A.F.; Morbini, M.; Borghi, C. Do we need 'new' omega-3 polyunsaturated fatty acids formulations? Expert Opin. Pharmacother. 2015, 16, 285-288. [CrossRef] [PubMed]

24. Adarme-Vega, T.C.; Thomas-Hall, S.R.; Schenk, P.M. Towards sustainable sources for omega-3 fatty acids production. Curr. Opin. Biotechnol. 2014, 26, 14-18. [CrossRef] [PubMed]

25. Kassis, N.M.; Gigliotti, J.C.; Beamer, S.K.; Tou, J.C.; Jaczynski, J. Characterization of lipids and antioxidant capacity of novel nutraceutical egg products developed with omega-3-rich oils. J. Sci. Food Agric. 2012, 92, 66-73. [CrossRef] [PubMed]

26. Tou, J.C.; Jaczynski, J.; Chen, Y.C. Krill for human consumption: Nutritional value and potential health benefits. Nutr. Rev. 2007, 65, 63-77. [CrossRef] [PubMed]

27. Lv, J.; Yang, X.; Ma, H.; Hu, X.; Wei, Y.; Zhou, W.; Li, L. The oxidative stability of microalgae oil (Schizochytrium aggregatum) and its antioxidant activity after simulated gastrointestinal digestion: Relationship with constituents. Eur. J. Lipid Sci. Technol. 2015, 117, 1928-1939. [CrossRef]

28. Ulleberg, E.K.; Comi, I.; Holm, H.; Herud, E.B.; Jacobsen, M.; Vegarud, G.E. Human gastrointestinal juices intended for use in in vitro digestion models. Food Dig. 2011, 2, 52-61. [CrossRef] [PubMed]

29. Holm, H.; Krogdahl, A.; Hanssen, L.E. High and low inhibitor soybean meals affect human duodenal proteinase activity differently: In vitro comparison of proteinase inhibition. J. Nutr. 1988, 118, 521-525. [PubMed]

30. Minekus, M.; Alminger, M.; Alvito, P.; Ballance, S.; Bohn, T.; Bourlieu, C.; Carriere, F.; Boutrou, R.; Corredig, M.; Dupont, D.; et al. A standardised static in vitro digestion method suitable for food-An international consensus. Food Funct. 2014, 5, 1113-1124. [CrossRef] [PubMed]

31. Lykkesfeldt, J. Determination of ascorbic acid and dehydroascorbic acid in biological samples by high-performance liquid chromatography using subtraction methods: Reliable reduction with tris[2-carboxyethyl]phosphine hydrochloride. Anal. Biochem. 2000, 282, 89-93. [CrossRef] [PubMed]

32. Fredrikson, M.; Carlsson, N.G.; Almgren, A.; Sandberg, A.S. Simultaneous and sensitive analysis of Cu, $\mathrm{Ni}, \mathrm{Zn}, \mathrm{Co}, \mathrm{Mn}$, and Fe in food and biological samples by ion chromatography. J. Agric. Food Chem. 2002, 50, 59-65. [CrossRef] [PubMed]

33. Jónsdóttir, R.; Geirsdottir, M.; Hamaguchi, P.Y.; Jamnik, P.; Kristinsson, H.G.; Undeland, I. The ability of in vitro antioxidant assays to predict the efficiency of a cod protein hydrolysate and brown seaweed extract to prevent oxidation in marine food model systems. J. Sci. Food Agric. 2016, 96, 2125-2135. [CrossRef] [PubMed]

34. Cavonius, L.R.; Carlsson, N.-G.; Undeland, I. Quantification of total fatty acids in microalgae: Comparison of extraction and transesterification methods. Anal. Bioanal. Chem. 2014, 406, 7313-7322. [CrossRef] [PubMed]

35. Alghazeer, R.; Gao, H.; Howell, N.K. Cytotoxicity of oxidised lipids in cultured colonal human intestinal cancer cells (caco-2 cells). Toxicol. Lett. 2008, 180, 202-211. [CrossRef] [PubMed]

36. Undeland, I.; Hultin, H.O.; Richards, M.P. Added triacylglycerols do not hasten hemoglobin-mediated lipid oxidation in washed minced cod muscle. J. Agric. Food Chem. 2002, 50, 6847-6853. [CrossRef] [PubMed] 
37. Hall, L.; Martinus, R.D. Hyperglycaemia and oxidative stress upregulate HSP60 \& HSP70 expression in hela cells. Springerplus 2013, 2, 431. [CrossRef] [PubMed]

38. Leibowitz, G.; Ktorza, A.; Cerasi, E. The role of txnip in the pathophysiology of diabetes and its vascular complications: A concise review. Medicographia 2014, 36, 391-397.

39. Larsson, K.; Tullberg, C.; Alminger, M.; Havenaar, R.; Undeland, I. Malondialdehyde and 4-hydroxy-2-hexenal are formed during dynamic gastrointestinal in vitro digestion of cod liver oils. Food Funct. 2016, 7, 3458-3467. [CrossRef] [PubMed]

40. Steppeler, C.; Haugen, J.-E.; Rødbotten, R.; Kirkhus, B. Formation of malondialdehyde, 4-hydroxynonenal, and 4-hydroxyhexenal during in vitro digestion of cooked beef, pork, chicken, and salmon. J. Agric. Food Chem. 2016, 64, 487-496. [CrossRef] [PubMed]

41. Ishikado, A.; Morino, K.; Nishio, Y.; Nakagawa, F.; Mukose, A.; Sono, Y.; Yoshioka, N.; Kondo, K.; Sekine, O.; Yoshizaki, T.; et al. 4-hydroxy hexenal derived from docosahexaenoic acid protects endothelial cells via Nrf2 activation. PLoS ONE 2013, 8, e69415. [CrossRef] [PubMed]

42. Mishra, A.; Chaudhary, A.; Sethi, S. Oxidized omega-3 fatty acids inhibit NF-kb activation via a PPAR $\alpha$-dependent pathway. Arterioscler. Thromb. Vasc. Biol. 2004, 24, 1621-1627. [CrossRef] [PubMed]

43. Roy, J.; Galano, J.M.; Durand, T.; Le Guennec, J.Y.; Lee, J.C. Physiological role of reactive oxygen species as promoters of natural defenses. FASEB J. 2017. [CrossRef] [PubMed]

44. Anderson, D.R.; Duryee, M.J.; Shurmur, S.W.; Um, J.Y.; Bussey, W.D.; Hunter, C.D.; Garvin, R.P.; Sayles, H.R.; Mikuls, T.R.; Klassen, L.W.; et al. Unique antibody responses to malondialdehyde-acetaldehyde (MAA)-protein adducts predict coronary artery disease. PLoS ONE 2014, 9, e107440. [CrossRef] [PubMed]

45. Jayathilake, A.G.; Senior, P.V.; Su, X.Q. Krill oil extract suppresses cell growth and induces apoptosis of human colorectal cancer cells. BMC Complement. Altern. Med. 2016, 16, 328. [CrossRef] [PubMed]

46. Costanzo, M.; Cesi, V.; Prete, E.; Negroni, A.; Palone, F.; Cucchiara, S.; Oliva, S.; Leter, B.; Stronati, L. Krill oil reduces intestinal inflammation by improving epithelial integrity and impairing adherent-invasive escherichia coli pathogenicity. Dig. Liver Dis. 2016, 48, 34-42. [CrossRef] [PubMed]

47. Lobraico, J.M.; DiLello, L.C.; Butler, A.D.; Cordisco, M.E.; Petrini, J.R.; Ahmadi, R. Effects of krill oil on endothelial function and other cardiovascular risk factors in participants with type 2 diabetes, a randomized controlled trial. BMJ Open Diabetes Res. Care 2015, 3, e000107. [CrossRef] [PubMed] 